\title{
Risk factors of preterm birth among mothers who gave birth in public hospitals of central zone, Tigray, Ethiopia: unmatched case-control study 2017/2018
}

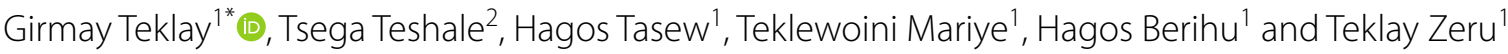

\begin{abstract}
Objective: The aim of the study was to identify the risk factors for preterm birth in public hospitals of the central zone, Tigray, Ethiopia 2017/2018.

Result: A total of 88 neonates who born preterm (cases) and 176 neonates who born term (controls) with their index mothers were included making a response rate of 100\%. About 84/88 (95.5\%) mothers in cases and 173/176 (98.3\%) in control had antenatal care follow up. Among them, 33 (39.3\%) cases and 102 (58\%) controls were had antenatal care follow up four times and above. In multiple logistic regression at P-value $<0.05$, mothers with ANC follow up less than four [AOR 95\% Cl 2.15 (1.19, 3.85)], mothers with pregnancy-induced hypertension [AOR 3.245; 95\% Cl (1.58, 6.67)], multiple pregnancy [AOR 2.47; 95\% Cl $(1.14,5.33)]$, fetal distress [AOR 4.0; $95 \% \mathrm{Cl}(1.9,8.2)]$ and birth defect [AOR $3.19 ; 95 \% \mathrm{Cl}(1.22,8.34)]$ were independent risk factors of preterm delivery.
\end{abstract}

Keywords: Preterm birth, Risk factors, Mothers, Central zone

\section{Introduction}

Preterm birth is demarcated as a delivery which occurs at less than 37 completed weeks of gestation or fewer than 259 days [1]. It is classified as extremely preterm ( $<28$ weeks), very preterm ( 28 to $<32$ weeks), and moderate ( 32 to $<34$ weeks) and late preterm ( 34 to $<37$ weeks) [2]. Preterm birth is a syndrome which can be classified into spontaneous preterm birth and provider-initiated preterm birth [2, 3].

Worldwide approximately 15 million babies are born too soon every year as a preterm birth and more than $60 \%$ of them were in sub-Saharan Africa and South Asia where health systems are weak in access and minimum health services utilization [4]. Even though there are many different causes of preterm-related neonatal death,

\footnotetext{
*Correspondence: girmeat@gmail.com

1 School of Nursing, College of Health Science and Comprehensive Specialized Hospital, Aksum University, Po Box:-298, Axum, Tigray, Ethiopia Full list of author information is available at the end of the article
}

greater than $75 \%$ of deaths are preventable without the need for intensive care $[5,6]$.

Preterm birth is the biggest cause of neonatal mortality worldwide and the second leading cause of underage five child deaths following pneumonia $[4,7,8]$. The incidence rates of preterm delivery were highest in Africa and North America, $11.9 \%$ and $10.6 \%$, respectively [9].

There is an intense survival gap for premature babies depending on where they are born $[3,10]$. Preterm birth is becoming the cause for economic instability in the family, community and the nation at large. It is not only resulted in economic burdens due to initial neonatal treatment but also in substantial costs to health services after discharge from the neonatal unit [3].

Being born preterm is a risk factor that put infants at higher risks of chronic diseases and death later in life [11]. Babies born preterm have continued to remain below the standard growth curve and demonstrate the reduced ability for catch-up growth in their life [12]. Moreover, preterm delivery and its consequences contribute to 
subsequent disabilities and neurological abnormalities to the infant's potential that may persist all over their lives amongst survivors $[2,12,13]$.

Socio-demographic factors, obstetric and gynecological-related factors, maternal medical disorder and common medical problems in neonates were some of them [9, 14-16]. Additionally, high levels of preterm birth in Africa are also possibly presented due to intrauterine infection or lack of availability of drugs, like Tocolytic agents [1].

Global progress for child survival and health cannot be achieved without addressing preterm birth [15]. This paper is important for policymaker by giving important information related to preterm birth to give intervention for prevention.

Despite the increase in ANC coverage and recommended guidelines for maternal and neonatal care, the number of preterm birth is increased through time. Even if there are limited studies which show the risk factors of preterm birth through the card review in some part of Ethiopia, the risk factors are different in different settings because of the difference in the healthcare system and demographic features. Consequently, this study was aimed to identify the risk factors for preterm birth in the central zone of Tigray.

\section{Main text}

\section{Study area and period}

The study was carried out in public hospitals of central zone Tigray, which has three hospitals named as St. Marry Hospital, Adwa Hospital, and Abyi Adi Hospital. We include 25 cases and 50 controls in Abyi Adi Hospital, 30 cases and 60 controls in Adwa Hospital and 33 cases and 66 controls in St. Marry Hospital. Data collection period was undertaken from December 2017 to February 2018.

\section{Study design}

A hospital-based un-matched retrospective case-control study design was employed.

\section{Source population}

All mothers who gave birth in public hospitals of the central zone of Tigray.

\section{Study population}

For cases All mothers with alive PTB ( 28 to $<37$ weeks) in public hospitals of the central zone of Tigray.

For controls All mothers with full-term birth ( $\geq 37$ weeks) at the same hospitals.

\section{Sample size and sampling technique}

A double population proportion formula (stat calc EPI info 7.1.1) was used with 95\% confidence level, $80 \%$ power and proportion of controls with exposure of previous history of preterm birth $36.36 \%$ [17], odds ratio 2.25 and case to control ratio were 1:2. The final sample size with adjustment for non-response rate of $10 \%$ was 264 (88 cases and 176 controls). Systematic sampling technique was used every two intervals in both cases and controls. The first participant was selected by lottery method. Confirmation of preterm birth admission was taken from the documentation and information from the staffs.

\section{Data collection tools and procedures}

Data was collected using interviewer-administered pretested semi-structured questionnaires and data recorded. The questionnaires were taken from different related studies [3,16-18] and necessary modifications were done to be applicable to the current study and population. A translated Tigrigna version questioner was used to collect data. Four B.Sc. Nurses for data collection and two MSc nurses for supervisor were recruited.

\section{Data quality control}

Training was given for data collectors and the questionnaires were pretested on $5 \%$ of the sample size at Suhul Hospital prior to the data collection period. Continuous follow-up and supervision were made by the supervisor and principal investigator. All participants were interviewed privately.

\section{Study variables \\ Dependent variable \\ - Preterm birth.}

\section{Independent variables}

- Maternal socio-demographic factors, gynecologic and obstetric related factors, maternal medical history of disorders, maternal emotional stress, infant's characteristics. Those information was obtained by face to face interview and record files.

\section{Operational definitions}

Preterm birth Those who born in $<37$ weeks.

\section{Diagnostic criteria for clinical conditions [19]}

- Gestational diabetes mellitus Fasting plasma glucose $\geq 126 \mathrm{mg} / \mathrm{dl}$.

- Pregnancy-induced hypertension Systolic blood pressure $\geq 130 \mathrm{~mm} \mathrm{Hg}$ and/or Diastolic blood pressure $\geq 90 \mathrm{~mm} \mathrm{Hg}$.

- Anemia Hemoglobin<11.0 g/dl. 
- Oligohydramnios Amniotic fluid index $<8$.

\section{Plan for data processing and analysis}

The data was cleaned, entered and edited using EPIDATA version 3.1 statistical software, then exported to SPSS Version 22.0 for analysis. Results were presented using tables and texts. Hosmer-Lemeshow test was used to check the appropriateness of the model for analysis. Variables which were show statistical significance during bivariate analysis at P-value $\leq 0.25$ were entered to multivariable logistic regression. Adjusted odds ratios (AOR) with $95 \% \mathrm{CI}$, were estimated to assess the strength of associations and statistical significance was declared at a $\mathrm{P}$-value $<0.05$.

\section{Result}

\section{Socio-demographic characteristics of respondents}

In this study, all the study participants were accepted to be part of the study which includes 88 preterm neonates (cases) and 176 term neonates (controls). The mean ( \pm standard deviation) age of mothers was $27 \pm 6$ years' ranges from 17 to 45 years. Most of the respondents 80 (90.9\%) cases and 166 (94.3\%) controls were orthodox. Regarding marital status, $79(89.8 \%)$ cases and 161 (91.5\%) of controls were married. About 60 (68.2\%) of cases and $131(74.4 \%)$ of controls were housewives by occupation and 25 (28.4\%) cases and $46(26.1 \%)$ of controls were not able to read and write (Table 1 ).

\section{Maternal obstetrics and fetal condition}

In our study 84 (95.5\%) cases and 173 (98.3\%) were had ANC follow up. Among them, 33 (39.3\%) cases and 102 (58\%) controls were had ANC follow up four times and above. Moreover, 64 (72.7\%) newborn from the cases and 139 (79\%) controls were born through Spontaneous vaginal delivery. About 50 (56.8\%) cases and 50 (28.4\%) of controls had one or more of pregnancy-related complications. Regarding the maternal emotional stress about $3(3.4 \%)$ cases and 9 (5.1\%) controls had maternal emotional stress, and 35 (39.8\%) mothers in cases and 59 (33.5\%) mothers in controls had lack of social support. About $13(14.8 \%)$ cases and 19 (10.8\%) of controls had one or more maternal medical problems. About 30 (34\%) cases and 17 (9.7\%) controls had fetal distress. All preterm neonates and 13 (12.9\%) of term neonates had a birth weight of $<2.5 \mathrm{~kg}$. Regarding the fetal presentation, $72(81.8 \%)$ cases and $151(85.8 \%)$ controls were in vertex presentation. From the total study participant, about $15(17 \%)$ cases and 9 (5.1\%) of controls had a birth defect (Table 2).

Table 1 Distribution of socio demographic characteristics among mothers who gave birth in public hospitals of central zone, Tigray, Ethiopia, 2018

\begin{tabular}{|c|c|c|c|c|}
\hline Variable & Category & Cases & Control & Total \\
\hline \multirow[t]{2}{*}{ Residence } & Urban & $46(52.3 \%)$ & 98 (55.7\%) & $144(54.5 \%)$ \\
\hline & Rural & $42(47.7 \%)$ & $78(44.3 \%)$ & $120(45.5 \%)$ \\
\hline \multirow[t]{5}{*}{ Age of the mother } & $\geq 19$ & $9(10.2 \%)$ & $16(9.1 \%)$ & $25(9.5 \%)$ \\
\hline & $20-24$ & $31(35.2 \%)$ & $51(29 \%)$ & $82(31.1 \%)$ \\
\hline & $25-29$ & $14(15.9 \%)$ & $53(30.1 \%)$ & $67(25.4 \%)$ \\
\hline & $30-34$ & $16(18.2 \%)$ & $31(17.6 \%)$ & $47(17.8 \%)$ \\
\hline & $\geq 35$ & $18(20.5 \%)$ & 25 (14.2\%) & $43(16.3 \%)$ \\
\hline \multirow[t]{5}{*}{ Educational status } & Can't read and right & $25(28.4 \%)$ & $46(26.1 \%)$ & $71(26.9 \%)$ \\
\hline & Read and right & $8(9.1 \%)$ & $20(11.4 \%)$ & $28(10.6 \%)$ \\
\hline & Primary school & $21(23.9 \%)$ & 39 (22.2\%) & $60(22.7 \%)$ \\
\hline & Secondary school & $26(29.5 \%)$ & $46(26.1 \%)$ & $72(27.3 \%)$ \\
\hline & College and above & $8(9.1 \%)$ & $25(14.2 \%)$ & $33(12.5 \%)$ \\
\hline \multirow[t]{3}{*}{ Marital status } & Unmarried & $6(6.8 \%)$ & $10(5.7 \%)$ & $16(6.1 \%)$ \\
\hline & Married & $79(89.8 \%)$ & $161(91.5 \%)$ & 240 (90.9\%) \\
\hline & Widowed/divorced & $3(3.4 \%)$ & $5(2.8 \%)$ & $8(3 \%)$ \\
\hline \multirow[t]{2}{*}{ Religion } & Orthodox & 80 (90.9\%) & $166(94.3 \%)$ & $246(93.2 \%)$ \\
\hline & Muslim & $8(9.1 \%)$ & $10(5.7 \%)$ & $18(6.8 \%)$ \\
\hline \multirow[t]{4}{*}{ Occupational status } & Housewife & $60(68.2 \%)$ & $131(74.4 \%)$ & $191(72.3 \%)$ \\
\hline & Governmental employee & $10(11.4 \%)$ & $17(9.7 \%)$ & $27(10.2 \%)$ \\
\hline & Private employee & $9(10.2 \%)$ & $10(5.7 \%)$ & $19(7.2 \%)$ \\
\hline & Daily/farmer/other & $9(10.2 \%)$ & $18(10.2 \%)$ & $27(10.2 \%)$ \\
\hline
\end{tabular}


Table 2 Maternal obstetrics and fetal condition among mothers who gave birth in public hospitals of central zone, Tigray, Ethiopia, 2018

\begin{tabular}{|c|c|c|c|c|}
\hline Variable & Category & Cases & Control & Total \\
\hline \multirow[t]{2}{*}{ ANC follow } & Yes & $84(95.5 \%)$ & $173(98.3 \%)$ & $257(93.5 \%)$ \\
\hline & No & $4(4.5 \%)$ & $3(1.7 \%)$ & $7(2.7 \%)$ \\
\hline \multirow[t]{2}{*}{ How many ANC follow } & $<4$ & $51(60.7 \%)$ & $74(42 \%)$ & $127(48.1 \%)$ \\
\hline & $\geq 4$ & $33(39.3 \%)$ & $102(58 \%)$ & $137(51.9 \%)$ \\
\hline \multirow[t]{4}{*}{ Birth interval } & No previous birth & $42(47.7 \%)$ & $77(43.8 \%)$ & $119(45.1 \%)$ \\
\hline & 12-24 months & $3(3.4 \%)$ & $5(2.8 \%)$ & $8(3 \%)$ \\
\hline & 24-36 months & $15(17.1 \%)$ & $33(18.8 \%)$ & $48(18.2 \%)$ \\
\hline & $\geq 36$ months & $28(31.8 \%)$ & $61(34.6 \%)$ & $89(33.7 \%)$ \\
\hline \multirow[t]{2}{*}{ Parity } & Prim gravida & $41(46.6 \%)$ & $76(43.2 \%)$ & $117(44.3 \%)$ \\
\hline & Multigravida & $47(53.4 \%)$ & $100(56.8 \%)$ & $147(55.7 \%)$ \\
\hline \multirow[t]{2}{*}{ Immediate last mode of delivery } & Spontaneous normal & $40(85.1 \%)$ & $81(81 \%)$ & $121(83.4 \%)$ \\
\hline & Indicated & $7(14.9 \%)$ & $19(19 \%)$ & $24(16.6 \%)$ \\
\hline \multirow[t]{3}{*}{ Immediate previous pregnancy outcome } & Preterm & $7(14.9 \%)$ & $12(12 \%)$ & $17(11.7 \%)$ \\
\hline & Still birth & $9(19.1 \%)$ & $10(10 \%)$ & $19(13.1 \%)$ \\
\hline & Normal birth & $31(66 \%)$ & $78(78 \%)$ & $109(75.2 \%)$ \\
\hline \multirow[t]{2}{*}{ Maternal RH factor } & Positive & $79(89.8 \%)$ & $152(86.4 \%)$ & $231(87.5 \%)$ \\
\hline & Negative & $9(10.2 \%)$ & $24(13.6 \%)$ & $33(12.5 \%)$ \\
\hline \multirow[t]{2}{*}{ Current mode of delivery } & Spontaneous normal & $64(72.7 \%)$ & $139(79 \%)$ & $203(76.9 \%)$ \\
\hline & latrogenic delivery & $24(27.4 \%)$ & $37(21 \%)$ & $61(23.1)$ \\
\hline \multirow[t]{2}{*}{ Current pregnancy has complication } & Yes & $50(56.8 \%)$ & $50(28.4 \%)$ & $100(37.9 \%)$ \\
\hline & No & $38(43.2 \%)$ & $126(71.6 \%)$ & $164(62.1 \%)$ \\
\hline \multirow{8}{*}{$\begin{array}{l}\text { Type of current pregnancy complication (multiple options } \\
\text { were possible) }\end{array}$} & Hypertension & $30(60 \%)$ & $18(36 \%)$ & $48(48 \%)$ \\
\hline & Multiple pregnancy & $22(44 \%)$ & $17(34 \%)$ & $39(39 \%)$ \\
\hline & Poly/oligo hydramnios & $5(10 \%)$ & $9(18 \%)$ & $14(14 \%)$ \\
\hline & PROM & $16(32 \%)$ & $15(30 \%)$ & $31(31 \%)$ \\
\hline & Meconium stained & $6(12 \%)$ & $8(16 \%)$ & $14(14 \%)$ \\
\hline & Maternal fever & $6(12 \%)$ & $10(20 \%)$ & $16(16 \%)$ \\
\hline & Cephalo-pelvic disproportion & $1(2 \%)$ & $8(16 \%)$ & $9(9 \%)$ \\
\hline & Placental previa & $1(2 \%)$ & $13(26 \%)$ & $14(14 \%)$ \\
\hline \multirow[t]{2}{*}{ Maternal emotional stress } & Yes & $3(3.4 \%)$ & $9(5.1 \%)$ & $12(4.5 \%)$ \\
\hline & No & $85(96.6 \%)$ & 167 (94.9\%) & $252(95.5 \%)$ \\
\hline \multirow[t]{2}{*}{ Maternal social support } & Lack of social support & $35(39.8 \%)$ & $59(33.5 \%)$ & $94(35.6 \%)$ \\
\hline & Have social support & $53(60.2 \%)$ & $117(66.5 \%)$ & $170(64.4 \%)$ \\
\hline \multirow[t]{2}{*}{ Maternal medical problem } & Yes & $13(14.8 \%)$ & $19(10.8 \%)$ & $32(12.1 \%)$ \\
\hline & No & $75(85.2 \%)$ & $157(89.2 \%)$ & $232(87.9 \%)$ \\
\hline \multirow[t]{3}{*}{ Type of medical problem (multiple options were possible) } & Anemia & $11(84.6 \%)$ & $11(57.9 \%)$ & $22(68.8 \%)$ \\
\hline & Malaria & $5(38.5 \%)$ & $10(52.6 \%)$ & $15(46.9 \%)$ \\
\hline & UTI & $10(76.9 \%)$ & $13(68.4 \%)$ & $23(71.9 \%)$ \\
\hline \multirow[t]{2}{*}{ Maternal height } & $\leq 150$ & $7(8 \%)$ & $31(17.6 \%)$ & $38(14.4 \%)$ \\
\hline & $>150$ & $81(92 \%)$ & $145(82.4 \%)$ & $226(85.6 \%)$ \\
\hline \multirow[t]{2}{*}{ Maternal MUAC } & $<19$ & $20(22.7 \%)$ & $48(27.3 \%)$ & $68(25.8 \%)$ \\
\hline & $\geq 19$ & $68(77.2 \%)$ & $128(72.7 \%)$ & $196(74.2 \%)$ \\
\hline \multirow[t]{2}{*}{ Sex infant } & Male & $53(60.2 \%)$ & $100(56.8 \%)$ & $153(58 \%)$ \\
\hline & Female & $35(39.8 \%)$ & $76(43.2 \%)$ & $111(42 \%)$ \\
\hline \multirow[t]{2}{*}{ Birth weight of infant } & $<2500 \mathrm{~g}$ & 88 (100\%) & $13(7.4 \%)$ & $101(38.3 \%)$ \\
\hline & $\geq 2500 \mathrm{~g}$ & & $163(92.6 \%)$ & $163(61.7 \%)$ \\
\hline \multirow[t]{2}{*}{ Fetal distress } & Yes & $30(34 \%)$ & $17(9.7 \%)$ & $47(17.8 \%)$ \\
\hline & No & $58(66 \%)$ & $159(90.3 \%)$ & $217(82.2 \%)$ \\
\hline
\end{tabular}


Table 2 (continued)

\begin{tabular}{|c|c|c|c|c|}
\hline Variable & Category & Cases & Control & Total \\
\hline \multirow[t]{2}{*}{ Fetal presentation } & Vertex & $72(81.8 \%)$ & $151(85.8 \%)$ & $223(84.5 \%)$ \\
\hline & Non vertex & $16(18.2 \%)$ & $25(14.2 \%)$ & $41(15.5 \%)$ \\
\hline \multirow[t]{2}{*}{ Congenital/birth defect } & Yes & $15(17 \%)$ & $9(5.1 \%)$ & $24(9.1 \%)$ \\
\hline & No & 73 (83\%) & $167(94.9 \%)$ & 240 (90.9\%) \\
\hline
\end{tabular}

\section{Risk factors associated with preterm birth}

In the bivariate logistic regression at $25 \%$ level of significance, number of ANC follow up, maternal height, birth defect, fetal distress, PROM, multiple pregnancies, pregnancy-induced hypertension were statically significant with preterm birth.

In multiple logistic regression at $\mathrm{P}$-value $<0.05$ using backward elimination method, mothers with ANC follow up less than four were two times more to give preterm birth than those who had greater than or equal to four ANC follow up (AOR 95\% CI $2.15(1.19,3.85)$. Mothers with pregnancy-induced hypertension were about three times higher to give preterm birth than those who had no hypertension [AOR 3.245; 95\% CI $(1.58,6.67)]$. The odds of a mother with multiple pregnancies were about two times more to give preterm birth than mothers with single pregnancy [AOR 2.47; 95\% CI $(1.14,5.33)]$. Neonate with fetal distress during labor and delivery were about four times higher to be preterm than those who had no fetal distress [AOR 4.0; $95 \%$ CI $(1.9,8.2)]$ and those who have birth defect were about three times higher to had a chance of preterm birth [AOR 3.19; 95\% CI $(1.22,8.34)$ ] (Table 3).

\section{Discussion}

The study was aimed to assess the risk factors for preterm birth in order to tackle the burden of the disease and its associated problems.

The lack of ANC diminishes the chance of identifying risks and provide appropriate interventions towards prevention of preterm delivery. Our finding revealed that women who follow ANC less than four times were about two times more to give preterm delivery as compared to women who attended ANC four times or more. This is consistent with the study done in Tanzania [20], Debremarkos Town Health Institution [17], western China [21], Gaza strip [22] and south-western Nigeria [23]. This could be due to the fact that women with regular ANC follow up may have more chance to early detection of severe diseases or obstetrics complications and appropriate case management. The regional government should enhance the awareness of women in ANC follow-up by increasing community ownership through women development army.

Our study revealed that mothers who had pregnancy induced hypertension had three times increased the risk of having a preterm birth than those mothers without pregnancy-induced hypertension. This finding is in line

Table 3 Factors associated with preterm birth among mothers who gave birth in public hospitals of central zone, Tigray, Ethiopia, 2018

\begin{tabular}{llllll}
\hline Variables & Category & Cases & Controls & COR (95\% Cl) & AOR (95\% Cl) \\
\hline Number of ANC follow up & $<4$ & $51(60.7 \%)$ & $74(42 \%)$ & $1.09(1.24,3.52)$ & $2.15(1.19,3.85)^{* *}$ \\
& $\geq 4$ & $33(39.3 \%)$ & $102(58 \%)$ & 1 & 1 \\
Pregnancy induced hypertension & Yes & $30(60 \%)$ & $18(36 \%)$ & $4.54(2.35,8.76)$ & $3.24(1.58,6.67)^{* *}$ \\
& No & $20(40 \%)$ & $32(64 \%)$ & 1 & 1 \\
Multiple pregnancy & Yes & $22(44 \%)$ & $17(34 \%)$ & $3.12(1.56,6.25)$ & $2.5(1.14,5.33)^{* *}$ \\
& No & $28(56 \%)$ & $33(66 \%)$ & 1 & 1 \\
Premature rapture of membrane & Yes & $16(32 \%)$ & $15(30 \%)$ & $2.38(1.12,5.08)$ & $1.02(0.39,2.68)$ \\
& No & $34(68 \%)$ & $35(70 \%)$ & 1 & $0.4(0.17,0.96)$ \\
Maternal height & $\leq 150 \mathrm{~cm}$ & $7(8 \%)$ & $31(17.6 \%)$ & $0.42(0.16,1.0)$ & 1 \\
Birth defect & $>150 \mathrm{~cm}$ & $81(92 \%)$ & $145(82.4 \%)$ & 1 & $3.20(1.22,8.32)^{* *}$ \\
Fetal distress & Yes & $15(17 \%)$ & $9(5.1 \%)$ & $3.81(1.59,9.11)$ & 1 \\
& No & $73(83 \%)$ & $167(94.9 \%)$ & 1 & $4.0(1.94,8.23)^{* *}$ \\
\hline
\end{tabular}

** Variable are significantly associated with preterm birth at P-value of $<0.05$ 
with studies conducted in Gondar [16], Debremarkos [17], southern India [19], western China [21] and southwestern Nigeria [23]. This could be due to hypertension decreases the uteroplacental blood floor which leads to intrauterine growth restriction that causes preterm delivery. The other reason might be due to complications of pregnancy-induced hypertension can cause vascular damage to the placenta, which induces the oxytocin receptors, results in preterm labor and delivery.

We found that mothers with multiple pregnancies had more than twofolds increasing the likelihood of having preterm delivery as compared to mothers with singleton delivery. This is consistent with the study done in Tanzania [20], south-western Nigeria [23]. Palestine [24], southern India [19], Gaza strip [22]. This is probably due to multiple pregnancies could over distend the uterus which stimulates early labor leading to preterm delivery.

In our finding the likelihood of preterm delivery among birth defect neonate were three times more significant than those who had no any birth defect. This could be due to the interaction of genetic and environmental risk factors contribute to preterm delivery. Identification of specific modifiable risk factors should be an important research and public health priority.

In this study, we find that fetal distress was about four times more significantly associated with preterm delivery. This finding is consistent with the study done in Jakarta [25]. Fetal distress infant could medically indicated to premature births as emergency births, where the decision to deliver must be made very quickly. Pregnancy-induced hypertension may decrease blood flow from mother's placenta which leads to hypoxemia in the fetus. This condition can lead to fetal distress.

\section{Conclusion}

The commonest obstetrical risk factor for preterm birth was hypertensive disorders of pregnancy and multiple pregnancies. Regarding to neonates, fetal distress and birth defect were the significant variables with preterm delivery. Early detection and treatment of diseases or disorders among pregnant women as well as the improving health care quality delivered to pregnant women may reduce risk factors for preterm delivery.

\section{Limitation}

Our study is limited to hospital-based quantitative study. It would be better if qualitative approach study was triangulated to investigate further factors on preterm birth.

\section{Abbreviations}

AOR: adjusted odd ratio; COR: crudes odd ratio; SPSS: Statistics Package for Social Science; ANC: antenatal care; PTB: preterm birth.

\section{Authors' contributions}

GT: conceived and designed the study, supervised the data collection, performed the analysis, interpretation of data and drafted the manuscript. TTA, HT:TM: HB and TZ were involved in assisting with the study design, analysis, and interpretation and reviewed the manuscript critically. All authors read and approved the final manuscript.

\section{Author details \\ ${ }^{1}$ School of Nursing, College of Health Science and Comprehensive Specialized Hospital, Aksum University, Po Box:-298, Axum, Tigray, Ethiopia. ${ }^{2}$ Department of Medical Laboratory, College of Health Science and Comprehensive Special- ized Hospital, Aksum University, Axum, Tigray, Ethiopia.}

\section{Acknowledgements}

Authors thanks to Aksum University and the data collectors, supervisors and study subjects.

\section{Competing interests}

The author declares that they have no competing interests.

\section{Availability of data and materials}

All data is available via this manuscript.

\section{Consent for publication}

Not applicable.

\section{Ethics approval and consent to participate}

The study was approved by the institutional research review board of Aksum University College of health science (AKU-CHS, IRB). An official permission was also secured to Tigray regional health bureau. Then a permission and support letter was written to the health office of the central zone of Tigray. The central zone of Tigray has only governmental hospitals and these hospitals were governs by Tigray regional health bureau. The official number from the regional health bureau was $216 / 1418 / 2010$ which is used for all three hospitals. This was written in the Ethiopian calendar in 19/04/2010 E.C. Respondents have informed the purpose of the study then information was collected after obtaining written parental informed consent in each participant. Written consent was wanted from all the informed respondents before the start of each interview. Respondents were allowed to refuse or discontinue or participation at any time they want. Information was recorded anonymously and confidentiality and beneficence were assured throughout the study period.

\section{Funding}

Aksum University was the source of funding (Grant No. AKU0001/2010).

\section{Publisher's Note}

Springer Nature remains neutral with regard to jurisdictional claims in published maps and institutional affiliations.

Received: 28 June 2018 Accepted: 7 August 2018

Published online: 13 August 2018

References

1. Lawn JE, et al. Born too soon: care for the preterm baby. Reprod Health. 2013;10:S5.

2. Blencowe $\mathrm{H}$, et al. Born Too Soon: The global epidemiology of 15 million preterm births. Reprod Health. 2013;10:S2.

3. Harrison MS, Goldenberg RL. Global burden of prematurity in seminars in fetal and neonatal medicine. New York: Elsevier; 2016.

4. Blencowe $\mathrm{H}$, et al. Born too soon: the global epidemiology of 15 million preterm births. Reprod Health. 2013;10(Suppl 1):S2.

5. Menon R. Preterm birth: a global burden on maternal and child health. Pathogens Glob Health. 2012;106(3):139.

6. Althabe F. Born too soon: the global action report on preterm birth World Health Organization. 2012.

7. Blencowe $\mathrm{H}$, et al. National, regional, and worldwide estimates of preterm birth rates in the year 2010 with time trends since 1990 for 
selected countries: a systematic analysis and implications. Lancet. 2012;379(9832):2162-72.

8. The Federal Democratic Republic of Ethiopia, Ethiopia Demographic and Health Survey, Central Statistical Agency, Addis Ababa, Ethiopia. 2016.

9. Beck S, et al. The worldwide incidence of preterm birth: a systematic review of maternal mortality and morbidity. Bull World Health Organ. 2010;88(1):31-8

10. European Parliamentary Forum, Prematurity: the hidden burden in reproductive health. Intell Brief. 2014; (Issue 12).

11. World Health Organization. Born too soon: the global action report on preterm birth. 2012

12. Gladstone M, Oliver C, Van den Broek N. Survival, morbidity, growth, and developmental delay for babies born preterm in low and middle-income countries - a systematic review of outcomes measured. PLoS ONE. 2015;10(3):e0120566.

13. Mwaniki MK, et al. Long-term neurodevelopmental outcomes after intrauterine and neonatal insults: a systematic review. Lancet. 2012;379(9814):445-52.

14. Password F. The spontaneous preterm birth of live born infants in women at low risk in Australia over 10 years: a population-based study. BJOG. 2007;114:731-5.

15. Chang $\mathrm{HH}$, et al. Preventing preterm births: trends and potential reductions with current interventions 39 very high human development index countries. Lancet. 2013;381(9862):223-34.

16. Gebreslasie K. Preterm birth and associated factors among mothers who gave birth in Gondar Town Health Institutions. Adv Nurs. 2016. 2016.
17. Bekele T, Amanon A, Gebreslasi K. Pre-term birth and associated factors among mothers who gave birth in Debremarkos Town Health Institutions, 2013 institutional based cross-sectional study. Gynecol Obstet. 2015;5(5):292-7.

18. Lu L, et al. Risk factors associated with late preterm births in the underdeveloped region of China: a cohort study and systematic review. Taiwanese J Obstet Gynecol. 2015;54(6):647-53.

19. Rao CR, et al. A case-control study on risk factors for preterm deliveries in a secondary care hospital, southern India. ISRN Obstet Gynecol. 2014;2014:935982.

20. Temu TB, et al. Maternal and obstetric risk factors associated with preterm delivery at a referral hospital in northern-eastern Tanzania. Asian Pac J Reprod. 2016;5(5):365-70

21. Zhang $X$, et al. Risk factors for preterm birth: a case-control study in a rural area of western China. Int J Clin Exp Med. 2015;8(3):4527.

22. Abu Hamad K, Abed Y, Hamad BA. Risk factors associated with preterm birth in the Gaza Strip: hospital-based case-control study. East Mediterr Health J. 2007:13(5):1132-41.

23. Akintayo $A$, et al. Preterm births in a resource-constrained setting: sociobiologic risk factors and perinatal outcomes. Ghana Med J. 2015;49(4):251-7.

24. Sarhan A, Anini H. Risk factors of preterm birth among Palestinian women: case-control study. J Nurs Care Qual. 2015;2:1-8.

25. Opitasari C, Andayasari L. Maternal education, prematurity and the risk of birth asphyxia in selected hospitals in Jakarta. Health Sci J Indonesia. 2015;6(2):111-5.
Ready to submit your research? Choose BMC and benefit from:

- fast, convenient online submission

- thorough peer review by experienced researchers in your field

- rapid publication on acceptance

- support for research data, including large and complex data types

- gold Open Access which fosters wider collaboration and increased citations

- maximum visibility for your research: over $100 \mathrm{M}$ website views per year

At $\mathrm{BMC}$, research is always in progress.

Learn more biomedcentral.com/submissions 